An examination of the glassy form of the ether under the polarizing microscope showed it to exhibit rather weak but definite extinction; it is, in fact, not completely amorphous, but possesses at least partial orientation of the molecules and appears to be polycrystalline on a very fine scale. An X-ray powder photograph of the material led to the same conclusion, the result (Fig. 2) being similar to that given by many polymers which include both crystalline and amorphous regions.

The substance, therefore, appears to have the unusual property of crystallizing to only a limited extent ; clearly it cannot be a polymer, nor is it likely to be at all highly associated, and the reason for this behaviour remains obscure at present. Further work to elucidate this is being carried out.

I wish to thank Prof. Wilson Baker for his interest, Dr. L. A. Duncanson for the infre-red measurements and Mr. C. W. Bunn and Dr. D. R. Holmes for the $\mathrm{X}$-ray examination and for helpful discussions.

Butterwick Research Laboratories,

$$
\text { D. J. C. WOOD }
$$

Imperial Chemical Industries, Ltd.,

The Frythe, Welwyn, Herts. Feb. 16.

1 Baker and Besly, J. Chem. Soc., 1103 (1940).

\section{Limits to a Firm's Control of Labour Turnover}

IN a recent article ${ }^{1}$, Dr. Hilde Behrend states that her findings on labour turnover point to the conclusion that "external factors, particularly the level of employment, are the decisive factors in this field", and that this conflicts with views recently put forward by Rice, Hill and Trist ${ }^{2}$, who are concerned with the way in which the characteristics of a particular firm may influence its turnover-rates. The difference in the interpretation of available data appears to have arisen in part through a different definition of internal and external determinants.

By the internal determinants of a system are generally meant those characteristics which define the structure and processes occurring within the system, as against the characteristics of its surrounding environment. A system is defined in terms of the elements of which it is composed, the characteristics of these elements and the relationship which exists between them. The internal determinants of a factory as a social system would, therefore, include the number of its employees, their characteristics such as sex and age, the nature of their work activities, etc., as well as the social and work relationships within the factory and its organizational structure. Dr. Behrend regards the first group of these characteristics as external, whereas Rice, Hill and Trist regard them as internal.

Dr. Behrend's conclusion that labour turnover is affected by existing employment opportunities is supported by the findings of Rice, Hill and Trist. This finding does not, however, explain variations in the rate of turnover between factories which, according to her data ${ }^{3}$, were found to range from 13 per cent in one factory, to 112 per cent in another factory, over a period of three months.

The turnover process can be regarded as an essential aspect of an employing organization which fulfils both the needs for efficient functioning of the organization and personal needs of its employees and staff.
It cannot be assumed that all firms will attempt to minimize their turnover-rates. The optimum turnover-rate will vary not only between factories but also for different types of employees within the same factory. A temporary rise in the number of persons who leave the firm may thus benefit firms who are suffering from a lag in turnover and at the same time seriously affect the efficiency of those firms the turnover-rates of which are already above the optimum. Similarly, a temporary fall in turnover. rates will be to the advantage of some firms, but not to others. The problem of labour turnover must, therefore, be considered with reference to the individual firm functioning within its environment.

P. G. HerbST

Tavistock Institute of Human Relations, London, W.1.

${ }^{2}$ Behrend, H., Nature, 173, 379 (1954).

3 Rice, A. K., Hill, J. M. M., and Trist, E. X., Human Relations, 3, No. 4 (1950); 4, No. 3 (1951); 4, No. 4 (1951); 5 No. 1 (1952) 5. No. 4 (1952); 6, No. 1 (1953).

3 Behrend, H., Occupational Psychology, 27, No. 2 (1953).

THE question raised in my article in Nature of February 27 was the problem of assessing the limits of the firm's control of labour turnover. P. G. Herbst's letter, it seems to me, merely confuses the issue.

It would appear that we both agree that there are three groups of determinants of labour turnover. Briefly, we may describe these as: (1) general economic and social factors operating in the whole society; (2) differences in the behaviour of people according to their sex, age, length of service and occupation; (3) specific internal factors character. istic of a particular firm and its management.

Herbst points out that Rice, Hill and Trist consider the second group to be internal factors, while I class them as external. My reason for doing this is a simple one. The differences in the behaviour of different types of employees are not restricted to a single firm. In practically all firms, old workers have a lower turnover than young ones, men have a lower wastage-rate than women, skilled workers behave differently from unskilled ones. These differences cannot be attributed to successful management or to good human and industrial relations within the firm. Furthermore, a firm can only change the composition of its work-force in the long run, and if it does, any ensuing reduction in labour turnover would not mean that the human relations in the firm have improved.

The problem is to what extent a firm can control labour turnover through its own policy. My findings suggest that the ability of the firm to reduce labour turnover is comparatively limited, and that external factors such as the level of employment are more powerful factors and, in fact, mould managerial and personnel policies.

Rice, Hill and Trist, on the other hand, although admitting that external events cause fluctuations in the level of turnover, brush them aside as 'undulations'. For a detailed examination of their arguments with regard to this point and to the statement that labour turnover is "a function of the institution", compare Behrend, J. Indust. Econ., 2, No. 1 (1953).

Faculty of Commerce and Social Science, HIIDE BEHREND

University, Birmingham 15. 